\title{
Genetic Divergence Studies in Bitter Gourd (Momordica charantia L.)
}

\author{
M. Lakshman Naik ${ }^{*}$, S. B. Chattopadhyay and Arup Chattopadhyay \\ Department of Vegetable Science, Bidhan Chandra Krishi Viswavidyalaya, \\ Mohanpur, Nadia, West Bengal, India \\ *Corresponding author
}

Keywords

Bitter gourd,

Genetic

Divergence,

$\mathrm{D}^{2}$, Genotypes,

Heterosis

Article Info

Accepted:

10 January 2021

Available Online:

10 February 2021
A study was carried out during the three consecutive years during spring-summer seasons (planting in mid of February) of 2015, 2016 and 2017 in New Alluvial Zone of West Bengal, at Horticultural Research Station, Mondouri, Bidhan Chandra Krishi Vishwavidyalaya, West Bengal, India, to evaluate the nature and magnitude of genetic divergence in 33 bitter gourd genotypes. Results revealed the presence of wide genetic diversity. The genotypes were grouped into 8 clusters based on Mahalanobis D2 statistics using Tocher's method. The clustering pattern of genotypes revealed that the genetic diversity was independent of the geographical diversity. Among the 8 clusters, maximum numbers of genotypes were found in cluster II, while clusters IV, VI, VII and VIII was found to be mono genotypic. Among the twenty quantitative characters studied, individual fruit Diameter constituted a maximum of $37.88 \%$ contribution to the divergence, followed by internode length. Ranking of genotypes based on intra-cluster mean performance for these characters which are major contributors of genetic diversity revealed its usualness in selecting parents for heterosis breeding.

\section{Introduction}

Bitter gourd (Momordica charantia L.) is an economically important member of the Cucurbitaceae family. It is extensively cultivated in India, China, Malaysia, Africa, and South America (Raj et al., 1993; Singh, 1990). Its primary centre of origin is Tropical Asia particularly Eastern India (includes the states of Odisha, West Bengal, Assam, Jharkhand and Bihar) and Southern China i.e., Indo Burma centre of origin (Zeven and Zhukovsky, 1975). The somatic chromosome number of bitter gourd is $2 n=2 x=22$. It is known by different names such as Bitter cucumber or Balsam pear in English, Karela in Hindi, Gujarathi and Punjabi, Karala in Bengali and Marathi, Kakara kaya in Telugu, Beet Karela in Assam, Hagalakayi in Kannada and Pavakai in Malayalam and Tamil.

The crop is highly cross pollinated due to monoecious nature. Other species belonging to this genus are $M$. dioca, $M$. cochinchinensis, M. balsamina, M. tuberosa, M. subangulata, M. denudata and $M$. macrocarpa. 
Inspite of the potential economic and medicinal importance of the crop, due attention has not been given towards a needbased crop improvement programme. However, recently the cultivation of bitter gourd has become increasingly popular, because of the growing awareness of its antidiabetic property and nutritive value among consumers. Due to the efforts of many vegetable breeders marked improvement in yield has been achieved and a good number of new varieties and hybrids have been developed. Nevertheless, there is a long way to go with bitter gourd improvement work specially to get resistant source for pest and disease. Therefore, the improvement work should be focused on selection of genotypes for better yield, superior quality and resistant to biotic stresses.

The yield potential of bitter gourd in India is very low due to poor yielding varieties and high incidence of pests and diseases. One of the approaches to improve yield and quality is heterosis breeding. The importance of heterosis breeding has been recognized widely in many vegetable crops. However, the pre-requisite of the heterosis breeding is the selection of the divergent. Information on heterosis and genetic divergence analysis is inadequate in bitter gourd. The information about the nature and magnitude of genetic divergence is essential for selection of diverse parents which upon hybridization can result in productive hybrids. Evaluation of available germplasm assumes importance in this regard and is necessary. Keeping foregoing points in view, a total of 33 bitter gourd genotypes were evaluated for the study of genetic divergence.

\section{Materials and Methods}

Thirty-three genotypes of bitter gourd selected from the germplasm collection obtained from NBPGR, Thrissur, India were grown in Randomized Block Design with three replications. for three consecutive years during spring-summer seasons (planting in mid of February) of 2015, 2016 and 2017 in New Alluvial Zone of West Bengal, at Horticultural Research Station, Mondouri, Bidhan Chandra Krishi Vishwavidyalaya. West Bengal, India. Seeds of the genotypes were sown at $100 \mathrm{~cm} \times 60 \mathrm{~cm}$ spacing in a plot size of $3.0 \mathrm{~m} \times 1.20 \mathrm{~m}$ accommodating ten plants per plot in each replication. Standard cultural practices for raising of good crops were followed (Chattopadhyay et al., 2007). Five competitive plant were randomly selected in each entry for recording observation Vine length $(\mathrm{cm})$, Number of primary branches, Internode length $(\mathrm{cm})$, Petiole length $(\mathrm{cm})$, Node no at first female flower appearance, Days to 50\% flowering, Sex ratio, Peduncle length $(\mathrm{cm})$, Days to first fruit harvest, Days to last fruit harvest, Number of marketable fruit harvest, Number of fruits/ plants, Fruit weight (g), Fruit length $(\mathrm{cm})$, Fruit dimeter $(\mathrm{cm}), 100$ seed weight $(\mathrm{g})$, Number of seed/fruits, Ascorbic acid (mg/100g), $\beta$ carotene content (mg/100g); Fruit yield/plant $(\mathrm{kg})$. The data were subjected to multivariate analysis of genetic divergence using Mahalanobis D2 statistic [Mahalanobis, P.C., 1936]. Grouping of entries was done by Tocher's method (Rao, 1952).

\section{Results and Discussion}

Mahalanobis (1936) developed the $\mathrm{D}^{2}$ Statistic model to determine the divergence among population in terms of generalized group distance. It has been widely used in Psychometry and anthropometry for classificatory purpose. Later, it has been successfully exploited in plant breeding. Multivariate analysis is a powerful tool in qualifying the degree of divergence between biological populations (genetic distance) and to assess the relative contribution of different components to the total divergence. Although, 
Mahalanobis's generalized distance as a measure of genetic distance occupy a unique place in plant breeding yet, as it happens in biology, several problems under the influence of random unpredictable changes due to environment, evade the direct grip of the concept well proven is more exact fields like mathematical components. It suggests the measuring the genetic distance through multivariate analysis over environment, to fortify its reliability.

Table.1 Clustering pattern of 33 genotypes of bitter gourd by Ward's method

\begin{tabular}{|c|c|c|}
\hline Cluster & $\begin{array}{c}\text { No. of } \\
\text { genotypes }\end{array}$ & Genotypes with source of collection \\
\hline I & 9 & $\begin{array}{l}\text { IC-44438 (NBPGR, Thrissur), IC-599423(NBPGR, Thrissur), IC- } \\
\text { 599426(NBPGR, Thrissur), IC-599424(NBPGR, Thrissur), IC- } \\
\text { 68343(NBPGR, Thrissur), IC-45350(NBPGR, Thrissur), IC- } \\
\text { 32817(NBPGR, Thrissur), IC-68285, IC-398610(NBPGR, Thrissur). }\end{array}$ \\
\hline II & 12 & $\begin{array}{l}\text { IC-541448(NBPGR, Thrissur), IC-536670(NBPGR, Thrissur), Dhaka } \\
\text { Karala (Local collection), IC-599420(NBPGR, Thrissur), IC- } \\
\text { 418486(NBPGR, Thrissur), IC-599421(NBPGR, Thrissur), IC- } \\
\text { 68236(NBPGR, Thrissur), IC-65787(NBPGR, Thrissur), IC- } \\
\text { 596983(NBPGR, Thrissur), IC-599428(NBPGR, Thrissur), K-85603 } \\
\text { (TCR-76) (NBPGR, Thrissur), IC-45358(NBPGR, Thrissur). }\end{array}$ \\
\hline III & 3 & $\begin{array}{l}\text { K-68237(NBPGR, Thrissur), IC-599424(NBPGR, Thrissur), Don No- } \\
\text { 1(Local collection). }\end{array}$ \\
\hline IV & 1 & IC-470557(NBPGR, Thrissur). \\
\hline $\mathbf{V}$ & 5 & $\begin{array}{l}\text { IC-467680(NBPGR, Thrissur), IC-427694(NBPGR, Thrissur), K- }-1 \text { - } \\
\text { 85608(NBPGR, Thrissur), IC-470565(NBPGR, Thrissur), IC- } \\
\text { 264699(NBPGR, Thrissur). }\end{array}$ \\
\hline VI & 1 & Gangajali Karala (Local collection). \\
\hline VII & 1 & IC-599429(NBPGR, Thrissur). \\
\hline VIII & 1 & IC-596981(NBPGR, Thrissur). \\
\hline
\end{tabular}

Table.2 Average Inter and intra cluster $\mathrm{D}^{2}$ values for eight clusters in 33 genotypes of bitter gourd

\begin{tabular}{|l|l|l|l|l|l|l|l|l|}
\hline Cluster & I & II & III & IV & V & VI & VII & VIII \\
\hline I & $\mathbf{7 . 4 1}$ & 17.39 & 10.69 & 9.27 & 12.30 & 15.88 & 16.39 & 11.30 \\
\hline II & & $\mathbf{8 . 0 5}$ & 11.95 & 18.54 & 14.54 & 10.70 & 12.99 & 14.81 \\
\hline III & & & $\mathbf{6 . 9 4}$ & 12.01 & 11.93 & 11.77 & 14.33 & 12.64 \\
\hline IV & & & & $\mathbf{0 . 0 0}$ & 16.81 & 16.13 & 19.86 & 11.78 \\
\hline V & & & & & $\mathbf{9 . 6 2}$ & 16.20 & 12.00 & 12.38 \\
\hline VI & & & & & & $\mathbf{0 . 0 0}$ & 14.60 & 16.10 \\
\hline VII & & & & & & & $\mathbf{0 . 0 0}$ & 12.23 \\
\hline VIII & & & & & & & & $\mathbf{0 . 0 0}$ \\
\hline
\end{tabular}


Table.3 Mean values of eight clusters for yield and its contributing characters

\begin{tabular}{|c|c|c|c|c|c|c|c|c|c|c|}
\hline \multirow[t]{2}{*}{ Cluster Number } & $\begin{array}{l}\text { VL } \\
(\mathbf{c m})\end{array}$ & NPB & IL (cm) & $\begin{array}{l}\text { PTL } \\
\text { (cm) }\end{array}$ & NNFF & DA50\%F & SR & $\begin{array}{l}\text { PDL } \\
\text { (cm) }\end{array}$ & DTFFH & DTLFH \\
\hline & 1 & 2 & 3 & 4 & 5 & 6 & 7 & 8 & 9 & 10 \\
\hline Cluster -1 & 196.44 & 11.26 & 5.39 & 4.89 & 14.78 & 41.81 & 8.11 & 4.71 & 67.93 & 110.04 \\
\hline Cluster -2 & 238.42 & 15.42 & 7.07 & 6.75 & 14.58 & 41.33 & 8.08 & 6.11 & 68.14 & 113.67 \\
\hline Cluster -3 & 236.56 & 12.56 & 6.31 & 5.73 & 15.44 & 42.56 & 7.81 & 4.99 & 68.22 & 108.33 \\
\hline Cluster -4 & 216.33 & 9.33 & 7.30 & 4.40 & 16.33 & 42.33 & 7.83 & 4.67 & 67.00 & 110.67 \\
\hline Cluster -5 & 186.33 & 11.27 & 4.63 & 6.14 & 14.60 & 41.53 & 8.19 & 5.97 & 68.07 & 112.07 \\
\hline Cluster -6 & 214.33 & 16.67 & 7.80 & 5.50 & 16.67 & 42.67 & 8.30 & 6.23 & 70.33 & 114.67 \\
\hline Cluster -7 & 165.33 & 15.67 & 5.67 & 6.03 & 16.00 & 41.33 & 8.37 & 4.33 & 67.33 & 105.67 \\
\hline Cluster -8 & 196.33 & 10.00 & 5.77 & 4.57 & 15.00 & 41.67 & 8.43 & 4.23 & 70.00 & 112.67 \\
\hline $\begin{array}{c}\% \text { Contribution } \\
\text { towards } \\
\text { divergence }\end{array}$ & $13.45 \%$ & $0.19 \%$ & $11.55 \%$ & $3.41 \%$ & $0.00 \%$ & $0.00 \%$ & $0.00 \%$ & $1.70 \%$ & $0.00 \%$ & $0.57 \%$ \\
\hline $\begin{array}{c}\text { Times Ranked } \\
\mathbf{1}^{\text {st }}\end{array}$ & 71 & 1 & 61 & 18 & 0 & 0 & 0 & 9 & 0 & 3 \\
\hline
\end{tabular}

\begin{tabular}{|c|c|c|c|c|c|c|c|c|c|c|}
\hline $\begin{array}{l}\text { Cluster } \\
\text { Number }\end{array}$ & NMFH & NFPP & FW(g) & $\begin{array}{c}\text { FL } \\
(\mathrm{cm})\end{array}$ & $\begin{array}{c}\text { FD } \\
(\mathbf{c m})\end{array}$ & $\begin{array}{c}100 \\
\text { SW (g) }\end{array}$ & NSPF & $\begin{array}{c}\text { AA } \\
\text { mg/100g }\end{array}$ & $\begin{array}{c}\mathrm{BC} \\
\mathrm{mg} / 100 \mathrm{~g}\end{array}$ & FYPP \\
\hline & 11 & 12 & 13 & 14 & 15 & 16 & 17 & 18 & 19 & 20 \\
\hline Cluster -1 & 8.48 & 14.19 & 57.74 & 12.64 & 10.12 & 18.21 & 18.15 & 76.41 & 0.92 & 0.91 \\
\hline Cluster -2 & 10.11 & 16.47 & 68.53 & 16.73 & 12.61 & 18.13 & 18.03 & 69.94 & 0.94 & 1.64 \\
\hline Cluster -3 & 9.56 & 15.89 & 62.33 & 15.98 & 10.80 & 16.58 & 18.67 & 75.76 & 0.76 & 1.08 \\
\hline Cluster -4 & 8.33 & 13.00 & 53.67 & 11.40 & 9.57 & 17.50 & 18.33 & 73.37 & 0.92 & 0.63 \\
\hline Cluster -5 & 8.80 & 14.40 & 67.34 & 15.56 & 11.89 & 18.64 & 17.93 & 76.13 & 0.78 & 1.17 \\
\hline Cluster -6 & 8.00 & 15.00 & 67.00 & 17.20 & 10.53 & 19.17 & 17.00 & 63.60 & 1.01 & 1.97 \\
\hline Cluster -7 & 8.33 & 13.67 & 70.00 & 17.37 & 13.37 & 15.10 & 16.67 & 61.93 & 1.00 & 1.43 \\
\hline Cluster -8 & 7.33 & 12.00 & 58.00 & 12.27 & 12.63 & 18.83 & 19.00 & 64.90 & 0.77 & 0.77 \\
\hline $\begin{array}{c}\% \\
\text { Contribution } \\
\text { towards } \\
\text { divergence }\end{array}$ & $0.00 \%$ & $0.00 \%$ & $0.00 \%$ & $10.98 \%$ & $37.88 \%$ & $1.70 \%$ & $0.38 \%$ & $11.55 \%$ & $1.52 \%$ & $5.11 \%$ \\
\hline $\begin{array}{c}\text { Times } \\
\text { Ranked 1st }\end{array}$ & 0 & 0 & 0 & 58 & 200 & 9 & 2 & 61 & 8 & 27 \\
\hline
\end{tabular}

1.VL (cm)- Vine length $(\mathrm{cm}) ; 2$. NPB- Number of primary branches; 3. IL (cm)- Internode length $(\mathrm{cm}) ; 4$. PTL $(\mathrm{cm})$ Petiole length (cm);5. NNFF-Node no at first female flower appearance; 6. DA50\%F- Days to 50\% flowering ;7. SR- Sex ratio; 8. PDL (cm)- Peduncle length (cm); 9. DTFFH- Days to first fruit harvest; 10. DTLFH- Days to last fruit harvest; 11. NMFH-Number of marketable fruit harvest; 12. NFPP-Number of fruits/ plants;13. FW(g)- Fruit weight (g);14. FL( cm)Fruit length $(\mathrm{cm}) ; 15$. FD $(\mathrm{cm})$ - Fruit diameter $(\mathrm{cm}) ; 16.100 \mathrm{SW}(\mathrm{g})-100$ seed weight $(\mathrm{g}) ; 17$. NSPF- Number of seed/fruits ;18. AA mg/100g - Ascorbic acid (mg/100g); 19. BC mg/100g- $\beta$ carotene content (mg/100g); 20. FYPP-Fruit yield/plant $(\mathrm{kg})$ 
The present study aimed at analyzing the genetic divergence of 33 genotypes employing twenty important quantitative characters. Based on the degree of divergence $\left(\mathrm{D}^{2}\right.$ values) between any two genotypes a logical grouping of the genotypes with low $\mathrm{D}^{2}$ value could be arrived at by Tocher's method as described by Rao (1952). The geographical diversity has been disapproved to be an index of genetic diversity in several crops (Mahto, 1996 and Shalini, 2000).

Based on the determination of divergence, all the 33 genotypes could meaningfully be grouped into 8 clusters (Table-1). Cluster II had 12 genotypes followed by cluster I had 9 genotypes, cluster $\mathrm{v}$ which comprised of 5 genotypes, cluster III had 3 genotypes. while cluster IV, VI, VII and VIII were monotypic. The monotypic genotypes in cluster IV, VI, VII and VIII indicated genotypes from those clusters might have originated across the geographical location in breeding programs. The grouping pattern of genotypes was observed to be random, indicating that geographical diversity and genetic divergence were unrelated. Therefore, the selection of genotypes for hybridization should be based on genetic divergence rather than geographic diversity.

The intra- and inter-cluster distances among 33 genotypes presented in Table- 2 revealed that cluster II had the most intra-cluster value (8.05) indicating genotypes included in the cluster were extremely diverse. Cluster IV, VI, VII and VIII showed the minimum intracluster value. At the inter-cluster level, minimum values occurred between cluster I and IV indicating close relationship among genotypes in those clusters. The greatest intercluster values were between cluster IV and VII followed by the distance between cluster II and IV indicating genotypes in those clusters had the greatest divergence.
Cluster means of genotypes (Table-3) indicated mean values of clusters varied in magnitude for all characters. The maximum cluster mean was in cluster VI for number of primary branches, internode length, node number at female flower appearance, days to $50 \%$ flowering, peduncle length, days to first fruit harvest, days to last fruit harvest, 100 seed weight, beta carotene content, fruit yield per plant. The maximum mean in cluster II was for vine length, petiole length, number of marketable fruit harvest, number of fruits per plant. Cluster II had the lowest for node number at female flower appearance and days to $50 \%$ flowering. These clusters could be useful sources of genes for simultaneous improvement of fruit yield, fruit quality. A high yielding, early flowering type, with better fruit quality could be bred utilizing genotypes from cluster II and VI as parents.

The relative contribution of individual characters towards genetic divergence was computed in terms of number of times it ranked first (Table-3). Fruit diameter contributed the most towards genetic divergence followed by vine length, internode length, ascorbic acid content, fruit length, fruit yield per plant, petiole length, 100 seed weight, peduncle length, beta carotene content, days to first fruit harvest, number of seed per fruit and number of primary branches indicating the possibility for selection of these characters (Table 3).

\section{References}

Chattopadhyay, A., Dutta, S., Bhattacharya, I., Karmakar, K., and Hazra, P. 2007. Technology for vegetable crop production. All Indian Coordinated Research Project on Vegetable Crops, Directorate of Research, Bidhan Chandra Krishi Viswavidyalaya, Kalyani- 741235, Nadia, West Bengal, India. 226p. 
Mahalanobis, P.C. 1936. On the generalized distance in statistics. Proceedings of the National Academy of Sciences, India. 2: 49-55.

Mahto, J.L., 1996. Genetic divergence and stability in Indian mustard under rainfed condition Journal of Maharashtra Agriculture University. 21(3): 334-337.

Raj, M., Prasanna, N.K.P., Peter, K.V. 1993. Bitter gourd Momordica ssp. In: Kalloo, G., Berg, B.O. (Eds.), Genetic Improvement of Vegetable Crops. Pergamon Press, Oxford, UK, pp. 239246.

Rao, C.R. 1952. Advance Statistical Methods in Biometrics. John Willey and Sons Pvt. Ltd., New York.

Shalini, T.S., Sheriff, R.A., Kulkarni, R.S., and Venkataravan, P. 2000. Genetic divergence in Indian mustard. Mysore Journal of Agriculture Sciences. 34: 251-256.

Singh, A., Singh, S.P., Bamezai, R. 1990. Bitter gourd (Momordica charantia) peel, pulp, seed and whole fruit extract inhibits mouse skin papilloma genesis. Toxicology Letters, 94: 37-46.

Zeven, A.C., and Zhukovsky, P.M. 1975. Dictionary of cultivated plants and their centers of diversity- Excluding Ornamentals, forest trees and lower plants, Wageningen: Centre for Agricultural publishing and documentation.

\section{How to cite this article:}

Lakshman Naik, M., S. B. Chattopadhyay and Arup Chattopadhyay. 2021. Genetic Divergence Studies in Bitter Gourd (Momordica charantia L.). Int.J.Curr.Microbiol.App.Sci. 10(02): 11441149. doi: https://doi.org/10.20546/ijcmas.2021.1002.135 